\title{
SIMULAÇÃO DO PROCESSO DE SECAGEM DE SEMENTES DE MILHO EM CAMADA FIXA
}

\author{
Cristiano Márcio Alves de Souza ${ }^{1,2 *}$; Daniel Marçal de Queiroz ${ }^{1,2}$; Adílio Flauzino de Lacerda \\ Filho ${ }^{1,2}$ \\ ${ }_{2}^{1}$ Depto. de Engenharia Agrícola - UFV - CEP: 36571-000 - Viçosa, MG. \\ ${ }^{2}$ Bolsista CNPq. \\ *Autor correspondente <csouza@alunos.ufv.br>
}

RESUMO: O processo de secagem realizado de maneira artificial é apontado por vários pesquisadores como um dos principais problemas de produção de sementes. Além disso, esse processo afeta também a qualidade dos grãos, diminuindo consideravelmente o seu valor de mercado para o consumo. $O$ objetivo deste trabalho foi desenvolver um modelo de simulação do processo de secagem de sementes de milho (Zea mays L.), validando-o por meio da comparação de resultados simulados com os de testes experimentais. O método de secagem utilizado consistiu em promover a pré-secagem das sementes nas espigas, posteriormente o produto permanecia em repouso durante 12 horas, sendo então as espigas debulhadas e complementada a secagem a granel, em silos com distribuição radial de ar. A temperatura média do ar de secagem foi de $42^{\circ} \mathrm{C}$ e a vazão específica de ar no secador de espigas foi de $44,8 \mathrm{~m}^{3} \mathrm{~min}^{-1} \mathrm{~m}^{-2}$ e, nos silos secadores de $5,9 \mathrm{~m}^{3} \mathrm{~min}^{-1} \mathrm{~m}^{-2}$. O modelo implementado apresentou respostas satisfatórias para a simulação de secagem de sementes de milho em espigas e a granel, considerando-se que o erro relativo médio foi de $10,88 \%$.

Palavras-chave: milho em espiga, secadores, modelagem matemática

\section{SIMULATION OF THE CORN SEED DRYING PROCESS IN FIXED BED}

\begin{abstract}
Artificial drying is one of the main problems of seed production, hence it affects quality of grains, and can decrease considerably their market value. This work aimed to develop a mathematical model to simulate a corn seed drying process. Simulation results were validated by comparison to experimental results. The drying method consisted of a fixed-bed, pre-drying of corn (Zea mays L.) ears, which were then kept on rest for 12 hours. After that the product was threshed and kernels were submitted to a final drying process on a fixed bed dryer: bins with radial air distribution. Air temperature was $42^{\circ} \mathrm{C}$; specific air rate of the ear corn dryer was $44.8 \mathrm{~m}^{3} \mathrm{~min}^{-1} \mathrm{~m}^{-2}$ and of the drying bin $5.9 \mathrm{~m}^{3} \mathrm{~min}^{-1} \mathrm{~m}^{-2}$. The error of the average simulation model was $10.88 \%$, which was considered satisfactory.
\end{abstract}

Key words: ear corn, dryer, mathematical model

\section{INTRODUÇÃO}

Dentre os métodos utilizados para conservação de grãos e sementes, a secagem é o mais econômico não só sob o ponto de vista de processamento, mas, também por permitir a preservação do produto em ambiente natural durante um longo período de tempo.

$\mathrm{Na}$ seqüência de colheita, secagem, armazenagem, manuseio e transporte a secagem é o passo crítico. Brooker et al. (1992) consideraram que, quando inadequada, a secagem constitui a principal causa de deterioração de sementes. Especificamente, ela pode ser responsável pelo aumento da susceptibilidade à quebra dos grãos de milho e de soja, e pelo decréscimo na qualidade de moagem de trigo e arroz. Aqueles autores concluíram que a secagem requer mais de $60 \%$ do total de energia utilizada na produção, enquanto os tratos culturais consomem $16 \%$, o plantio e cultivos $12 \%$, a colheita $6 \%$ e o transporte $6 \%$.

A produção de sementes de qualidade é muito importante dentro do processo de produção agrícola, pois se bem executada ela permite se obter estande uniforme e boa distribuição de plantas.

Além de ser o processo mais utilizado para possibilitar a preservação da qualidade dos produtos agrícolas, a secagem pode ser vista, também, como a operação que permite obter sementes de melhor qualidade, possibilitando colheitas antecipadas, além de evitar as deteriorações que poderiam ocorrer no campo (Toledo \& Marcos Filho, 1977 e Rossi \& Roa, 1980).

Montross et al. (1997) estudaram o desempenho de secadores de fluxos contínuos em função do préaquecimento dos grãos, na secagem de milho. Verificaram que, durante o pré-aquecimento, ocorreram decréscimos no teor de água do produto e que o incremento na temperatura dos grãos reduziu o índice de trincas. Concluíram que é mais econômico adquirir um sistema de pré-aquecimento do que um secador de alta capacidade, considerando-se as mesmas condições do trabalho.

A utilização de modelos matemáticos, para simular o processo de secagem em secadores que operam em alta temperatura, tem se tornado uma 
ferramenta importante para os engenheiros que trabalham na área de secagem e armazenagem de grãos (Queiroz et al., 1999).

Vários modelos estão à disposição dos usuários. O modelo proposto por Thompson et al. (1968) é um modelo semi-teórico utilizado com sucesso na simulação da secagem de produtos agrícolas. Esse modelo é capaz de prever a influência das condições do ar de secagem, da espessura da camada e do teor de água inicial do produto no processo de secagem (Queiroz, 1984).

Considerando que as condições pelas quais o produto passa durante o processo de secagem tem efeito direto sobre sua qualidade final, este trabalho teve por objetivo implementar um modelo de simulação do processo de secagem de sementes de milho nas espigas e realizar testes experimentais para obter os dados a serem utilizados na validação do modelo implementado.

\section{MATERIAL E MÉTODOS}

O trabalho foi realizado no Departamento de Engenharia Agrícola da Universidade Federal de Viçosa e em uma unidade de beneficiamento de sementes da empresa Sementes Agroceres S. A., localizada no município de Bandeirantes, no Estado do Paraná, e foi realizado em escala comercial.

Um programa computacional orientado a objetos, com interface do usuário amigável e flexível foi desenvolvido para simular o processo de secagem de sementes de milho. A linguagem de programação MS (Visual Basic, 1998) foi utilizada no desenvolvimento do programa computacional.

O modelo foi implementado com base no proposto por Thompson et al. (1968). Nesse modelo foi utilizada, como artifício, a divisão do processo de secagem em vários subprocessos. O leito de sementes foi considerado como formado por várias camadas com espessuras reduzidas, colocadas umas sobre as outras. As variações nas condições do ar e do grão, em cada camada, foram calculadas com base em pequenos incrementos de tempo.

A Figura 1 apresenta um esquema ilustrando como ocorreram as variações consideradas na simulação de secagem de uma camada de espessura reduzida, que compõe um leito de sementes. Quando o ar passa pela camada fina, durante determinado intervalo de tempo, certa quantidade de água do produto é evaporada, passando para o ar. Nesse intervalo, a temperatura do ar diminui, em conseqüência da transferência de calor sensível do ar para o aquecimento da semente, e do calor latente fornecido para evaporação parcial da água do produto. A quantidade de água perdida pelo produto é calculada por meio de uma equação empírica de secagem em camada delgada. As temperaturas finais do ar e da semente, consistentes com o resfriamento evaporativo, são obtidas por meio de balanços de energia.

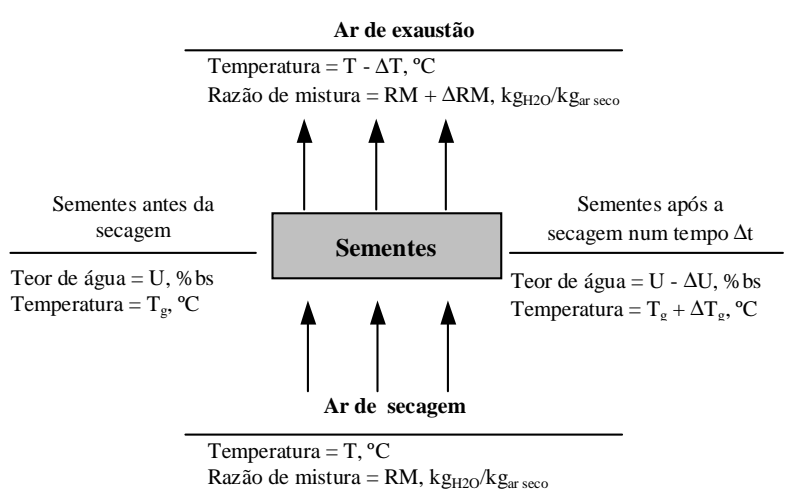

Figura 1 - Variações decorrentes do processo de secagem em camada delgada durante um intervalo de tempo $\Delta$ t.

Para desenvolver o modelo foram feitas as seguintes suposições: a secagem de uma camada delgada de produto pode ser descrita por uma equação obtida empiricamente; a temperatura da semente é igual à temperatura do ar que a envolve, após os balanços de energia, que levam em conta o resfriamento proveniente da evaporação da água do produto e das temperaturas das sementes e do ar; o teor de água de equilíbrio das sementes depende da temperatura e da umidade relativa do ar nas vizinhanças destas; a entalpia de vaporização da água nas sementes depende da temperatura e do teor de água destas; a entalpia específica das sementes depende do teor de água.

A seguir, apresentam-se os passos que foram executados para simular a secagem de uma camada de sementes.

Passo 1 - Cálculo da temperatura de equilíbrio entre o ar e semente, considerando somente a troca de calor sensível.

Para essa determinação, faz-se necessário o seguinte balanço de energia (equação 1):

$0,24 \cdot T_{0}+W_{0} \cdot\left(588+0,45 \cdot T_{0}\right)+C_{p} \cdot R \cdot(1+U) \cdot T_{g 0}=$

$0,24 \cdot T_{e}^{0}+W_{0} \cdot\left(588+0,45 \cdot T_{e}\right)+C_{p}^{p} \cdot R \cdot(1+U) \cdot T_{g e}^{g 0}$

em que, $T_{0}$ - temperatura do ar na entrada da camada de sementes, ${ }^{\circ} \mathrm{C} ; \mathrm{W}_{0}$ - razão de mistura do ar na entrada da camada de sementes, $\mathrm{kg}$ de vapor d'água por $\mathrm{kg}$ de ar seco; $\mathrm{T}_{\mathrm{g} 0}$ - temperatura da semente no instante $\mathrm{t},{ }^{\circ} \mathrm{C}$; $\mathrm{T}_{\mathrm{e}}$ - temperatura do ar em equilíbrio com a semente, ${ }^{\circ} \mathrm{C}$; $\mathrm{T}_{\mathrm{e}}^{\mathrm{e}}$ - temperatura da semente em equilíbrio com o ar, ${ }^{\circ} \mathrm{C}$; $U^{\text {ge }}$ - teor de água da semente no tempo t, decimal b.s.; $\mathrm{C}_{\mathrm{p}}$ - entalpia específica do milho, $\mathrm{kJ} \mathrm{kg}^{-1}{ }^{\circ} \mathrm{C}^{-1} ; \mathrm{R}$ - razão entre a massa de matéria seca da camada de sementes e a massa de ar seco que passa no intervalo de tempo $\Delta \mathrm{t}, \mathrm{kg} \mathrm{kg}^{-1}$.

Admitindo-se que a temperatura da semente é igual à temperatura do ar que a envolve, tem-se (equação 2):

$\mathrm{T}_{\text {ge }}=\mathrm{T}_{\mathrm{e}}$ 
A razão entre as massas de matéria seca e de ar seco foi determinada no início da simulação por meio da equação 3 :

$$
\mathrm{R}=\frac{\mathrm{P} \cdot \mathrm{v}_{\mathrm{e}} \cdot \mathrm{A} \cdot \Delta \mathrm{x}}{\mathrm{Q} \cdot \Delta \mathrm{t} \cdot 60 \cdot\left(1+\mathrm{U}_{0}\right)}
$$

em que, $U_{0}$ - teor de água inicial, decimal b.s.; $\Delta x$ espessura da camada de sementes, $m$; $\Delta t$ - incremento de tempo, $\mathrm{h} ; \mathrm{P}$ - massa específica do produto no início da secagem, $\mathrm{kg} \mathrm{m}^{-3} ; \mathrm{Q}$ - vazão de ar, $\mathrm{m}^{3} \min ^{-1} ; \mathrm{A}$ - área da seção transversal, $m^{2} ; v_{e}$ - volume específico do ar, $\mathrm{m}^{3} \mathrm{~kg}^{-1}$.

A entalpia específica do milho é função de seu teor de água e foi estimada por meio da equação 4.

$\mathrm{C}_{\mathrm{p}}=\left[0,35+\frac{0,851 \cdot \mathrm{U}}{1+\mathrm{U}}\right] \cdot 4,1868$

A temperatura de equilíbrio entre 0 ar de secagem e o produto foi determinada, por Thompson et al. (1968), por meio da equação de balanço de calor (equação 5).

$\mathrm{T}_{\mathrm{e}}=\frac{(0,24+0,45 \cdot \mathrm{RU}) \cdot \mathrm{T}_{0}+\mathrm{C}_{\mathrm{p}} \cdot \mathrm{R} \cdot(1+\mathrm{U}) \cdot \mathrm{T}_{\mathrm{g} 0}}{0,24+0,45 \cdot \mathrm{RU}+\mathrm{C}_{\mathrm{p}} \cdot \mathrm{R} \cdot(1+\mathrm{U})}$

em que, RU - razão de umidade, adm.

Passo 2 - Para calcular a o teor de água de equilíbrio do produto é necessário determinar primeiramente a umidade relativa do ar. Para isso, foi utilizada a equação apresentada por Brooker et al. (1992):

$$
\mathrm{U}_{\mathrm{r}}=\frac{100 \cdot \mathrm{P}_{\mathrm{atm}} \cdot \mathrm{W}_{0}}{\left(0,622+\mathrm{W}_{0}\right) \cdot \mathrm{P}_{\mathrm{vs}}}
$$

em que, $U_{r}$ - umidade relativa do ar, \%; $P_{a t m}$ - pressão atmosférica, $\mathrm{kPa} ; \mathrm{P}_{\mathrm{vs}}$ - pressão de vapor de saturação do ar, à temperatura $\mathrm{T}_{\mathrm{e}}, \mathrm{kPa} ; \mathrm{W}_{0}$ - razão de mistura do ar na entrada da camada de sementes, $\mathrm{kg}$ de vapor d'água por kg de ar seco.

A pressão de vapor de saturação do ar foi determinada pela equação 7 , apresentada pela ASAE Standard D271.2 (1998):

$\mathrm{T}_{\mathrm{e}}-255,38=\sum_{\mathrm{i}=0}^{8} \mathrm{~A}_{\mathrm{i}}\left[\ln \left(0,00145 \mathrm{P}_{\mathrm{vs}}\right)\right]^{\mathrm{i}}$

em que, $A_{0}=19,5322 ; A_{1}=13,6626 ; A_{2}=1,1768 ; A_{3}=-$ 0,$1897 ; A_{4}=0,08745 ; A_{5}=-0,01741 ; A_{6}=0,0021477 ; A_{7}=-$ $0,1383.10^{-3} ; A_{8}=0,38 \cdot 10^{-5}$.

Passo 3 - Cálculo do teor de água de equilíbrio

O teor de água de equilíbrio depende da temperatura e da umidade relativa do ar que circunda as sementes. Para descrever a umidade de equilíbrio das sementes a granel, foi proposta a equação 8 .
$\mathrm{U}_{\mathrm{e}}=1,206 \cdot\left[\frac{-\ln \left(1-0,01 \cdot \mathrm{U}_{\mathrm{r}}\right)}{\mathrm{T}_{\mathrm{e}}+45,6}\right]^{0,5}$

em que, $U_{e}$ - teor de água de equilíbrio das sementes de milho, decimal b.s.

Para estimar os valores do teor de água de equilíbrio das sementes de milho nas espigas foi utilizada a equação 9, proposta por Sharaf-Eldeen et al. (1980), conforme segue:

$\mathrm{U}_{\mathrm{e}}^{*}=5,69 \cdot\left[\frac{-\ln \left(1-\mathrm{U}_{\mathrm{r}}\right)}{\mathrm{T}_{\mathrm{e}}+273,16}\right]^{0,55}$

em que, $U_{e}{ }^{*}$ - teor de água de equilíbrio do milho em espigas, decimal b.s.

Passo 4 - Cálculo do tempo equivalente

O tempo equivalente é definido como o intervalo de tempo que o produto deveria ficar exposto às condições existentes, no tempo $t\left(T_{e}, W_{0}\right)$, para que o teor de água fosse reduzido do valor inicial $\left(U_{0}\right)$ para o valor atual $(U)$. Para se determinar o tempo equivalente na secagem de milho a granel usou-se a seguinte equação empírica (equação 10):

$\mathrm{t}=\mathrm{A} \cdot \ln (\mathrm{RU})+\mathrm{B} \cdot[\ln (\mathrm{RU})]^{2}$

em que, $\mathrm{t}$ - tempo de secagem, $\mathrm{h}$; $\mathrm{A}$ e $\mathrm{B}$ - parâmetros dependentes da temperatura do ar.

Os parâmetros A e B, obtidos a partir das curvas de secagem do milho a granel, foi calculados por meio das equações 11 e 12 .

$A=-1,706+0,0088 . T$

$B=-148,7 \cdot e^{(-0,059 \cdot T)}$

em que, $\mathrm{T}$ - temperatura do ar de secagem, ${ }^{\circ} \mathrm{C}$.

A equação utilizada para se determinar o tempo equivalente para secagem de sementes de milho nas espigas (equação 13) foi aquela obtida por Sharaf-Eldeen et al. (1980), que é válida na faixa de temperatura do ar de secagem entre 35,0 e $74,0^{\circ} \mathrm{C}$.

$R U=A \cdot e^{-k_{d} \cdot t}+(1-A) \cdot e^{-B \cdot k_{d} \cdot t}$

em que, $A=0,8459$ e $B=0,1278$ - constantes para o milho nas espigas; $k_{d}$ - parâmetro dependente da temperatura do ar de secagem e do teor de água do produto.

Como não foi possível isolar o termo t na equação 13 , foi usado o método de Newton-Raphson para obtê-lo.

Nas equações empíricas de secagem em camada delgada podem aparecer outras variáveis, como por exemplo o teor de água inicial do produto e/ou a velocidade do ar. Em algumas equações, também, o efeito da umidade relativa do ar é desprezado. 
A razão de umidade do produto foi calculada para o tempo t, conforme a equação 14:

$$
\mathrm{RU}_{0}=\frac{\mathrm{U}-\mathrm{U}_{\mathrm{e}}}{\mathrm{U}_{0}-\mathrm{U}_{\mathrm{e}}}
$$

Passo 5 - Cálculo da nova razão de umidade do produto A razão de umidade do produto, após secagem às condições de $\operatorname{ar} \mathrm{T}_{\mathrm{e}}$ e $\mathrm{W}_{0}$, durante um intervalo $\Delta \mathrm{t}$, de tempo, foi determinada pela equação empírica de secagem em camada delgada (equação 15), conforme a seguir:

$R U_{f}=f\left(T_{e}, U R, t_{e}+\Delta t\right)$

em que, $R U_{f}$ - razão de umidade final do produto, adm.

Passo 6 - Cálculo da umidade do produto no tempo $t+$ $\Delta \mathrm{t}$, (equação 16):

$\mathrm{U}_{\mathrm{f}}=\mathrm{RU}_{\mathrm{f}} \cdot\left(\mathrm{U}_{0}-\mathrm{U}_{\mathrm{e}}\right)+\mathrm{U}_{\mathrm{e}}$

em que, $U_{f}$ - teor de água do produto na camada, no tempo $\mathrm{t}+\Delta \mathrm{t}$.

Passo 7 - Cálculo da nova razão de mistura do ar

A razão de mistura do ar consistente com a perda de umidade do produto foi determinada por um balanço de massa (equação 17):

$\mathrm{W}_{\mathrm{f}}=\mathrm{W}_{0}+\mathrm{R} \cdot\left(\mathrm{U}-\mathrm{U}_{\mathrm{f}}\right)$

em que, $W_{f}$ - razão de mistura do ar na saída da camada de sementes, $\mathrm{kg}$ de vapor d'água por $\mathrm{kg}$ de ar seco.

Passo 8 - Cálculo das temperaturas finais do ar e do produto

As temperaturas finais do ar e do produto foram determinadas por meio de um balanço de energia que leva em conta a perda de umidade das sementes (equação 18):

$0,24 \cdot \mathrm{T}_{\mathrm{e}}+\mathrm{W}_{0} \cdot\left(588+0,45 \cdot \mathrm{T}_{\mathrm{e}}\right)+\mathrm{C}_{\mathrm{p}} \cdot \mathrm{R} \cdot(1+\mathrm{U}) \cdot \mathrm{T}_{\mathrm{ge}}+\left(\mathrm{W}_{\mathrm{f}}-\mathrm{W}_{0}\right) \cdot \mathrm{T}_{\mathrm{ge}}=$ $0,24 \cdot T_{f}+W_{f} \cdot\left(588+0,45 \cdot T_{f}\right)+C_{p} \cdot R \cdot(1+U) \cdot T_{g f}+\left(W_{f}-W_{0}\right) \cdot \Delta L_{v}$

em que, $T_{f}$ - temperatura do ar saindo da camada de sementes, ${ }^{\circ} \mathrm{C} ; \mathrm{T}_{\mathrm{f}}$ - temperatura do produto na camada no tempo $\mathrm{t}+\Delta \mathrm{t}$, ${ }^{\circ} \mathrm{C} ; \Delta \mathrm{L}_{v}$ - entalpia latente de vaporização acima do valor para evaporação da água livre, $\mathrm{kJ} \mathrm{kg}^{-1}$ de água.

A entalpia latente de vaporização da água nas sementes a granel, depende da sua temperatura e teor de água, e foi estimada pela equação 19:

$\Delta \mathrm{L}_{\mathrm{v}}=(606-0,57 \cdot \mathrm{T}) \cdot\left[4,35 \cdot \mathrm{e}^{(-28,25 \cdot \mathrm{U})}\right] \cdot 4,1868$

em que, $\Delta \mathrm{L}_{\mathrm{v}}$ - entalpia latente de vaporização da água do milho, $\mathrm{kJ} \mathrm{kg}^{-1}$.

A equação 20 , utilizada para determinar a entalpia latente de vaporização da água do milho nas espigas, foi desenvolvida utilizando-se a metodologia proposta por Damaceno et al. (1981).

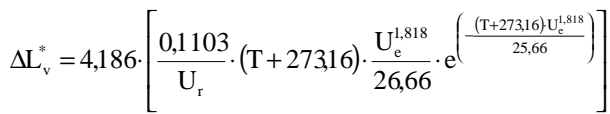

em que, $\Delta \mathrm{L}_{\mathrm{v}}^{*}$ - entalpia de vaporização da água do milho em espiga, $\mathrm{kJ} \mathrm{kg}^{-1}$.

O primeiro e segundo termo de cada lado da equação 18 representam as entalpias inicial e final do ar. O terceiro termo de cada lado da equação representa a energia contida no produto, nos tempos $t$ e $t+\Delta$ t. O quarto termo do lado esquerdo da igualdade representa a quantidade de energia contida na água que está sendo retirada do produto. O último termo da equação representa a quantidade de energia adicional necessária para evaporar a água do produto, acima da quantidade necessária para evaporar a água livre.

Admitindo-se que a temperatura da semente nas espigas é igual à do ar que a envolve, tem-se:

$$
\mathrm{T}_{\mathrm{gf}}=\mathrm{T}_{\mathrm{f}}
$$
equação 22:

Explicitando $T_{f}$, na equação 18 obtém-se a $T_{f}=\frac{\left(0,24+0,45 \cdot W_{0}\right) \cdot T_{e}-\left(W_{f}-W_{0}\right) \cdot\left(588+\Delta L_{v}-T_{e}\right)+C_{p} \cdot R \cdot(1+U) \cdot T_{e}}{0,24+0,45 \cdot W_{f}+C_{p} \cdot R \cdot(1+U)}$

Passo 9 - Verificação da consistência dos valores de $T_{f}$ e $W_{f}$

Efetuados todos esses cálculos, é necessário verificar se o resultado obtido é factível. Em certos casos, podem-se obter resultados em que a umidade relativa do ar, determinada matematicamente, é superior a $100 \%$. Se isso ocorrer, novos balanços de massa e de energia deverão ser feitos, simulando a condensação de água no produto.

Nesses novos balanços, o ponto de estado $T_{f} e$ $\mathrm{W}_{\mathrm{f}}$, não factível, será corrigido para o ponto de estado $\mathrm{T}_{\mathrm{f}}^{*}$ e $\mathrm{W}_{\mathrm{f}}^{*}$. Esses novos balanços são representados pelas equações 23 e 24 :

$0,24 \cdot \mathrm{T}_{\mathrm{f}}+\mathrm{W}_{\mathrm{f}} \cdot\left(588+0,45 \cdot \mathrm{T}_{\mathrm{f}}\right)+\left(\mathrm{W}_{\mathrm{f}}^{*}-\mathrm{W}_{\mathrm{f}}\right) \cdot \mathrm{T}_{\mathrm{f}}+\mathrm{C}_{\mathrm{p}} \cdot \mathrm{R} \cdot(1+\mathrm{U}) \cdot \mathrm{T}_{\mathrm{f}}=$ $0,24 \cdot \mathrm{T}_{\mathrm{f}}^{*}+\mathrm{W}_{\mathrm{f}}^{*} \cdot\left(588+0,45 \cdot \mathrm{T}_{\mathrm{f}}^{*}\right)+\mathrm{C}_{\mathrm{p}} \cdot \mathrm{R} \cdot(1+\mathrm{U}) \cdot \mathrm{T}_{\mathrm{f}}^{*}$

$\mathrm{Na}$ equação 23 , existem duas variáveis a serem determinadas, $\mathrm{T}_{\mathrm{f}}^{*}$ e $\mathrm{W}_{\mathrm{f}}^{*}$. A outra condição usada para tornar possível a determinação do ponto de estado factível, é que a umidade relativa determinada matematicamente seja, no máximo, igual a $100 \%$.

A quantidade de água condensada no produto faz com que o seu teor de água passe a ser $U_{\mathrm{f}}^{*}$, conforme equação 24 :

$$
\mathrm{U}_{\mathrm{f}}^{*}=\mathrm{U}_{\mathrm{f}}-\frac{\mathrm{W}_{\mathrm{f}}^{*}-\mathrm{W}_{\mathrm{f}}}{\mathrm{R}}
$$


Para avaliar os desvios entre os resultados simulados e os obtidos experimentalmente, utilizou-se o erro relativo, conforme a seguinte equação:

$E_{r}=100 \frac{\left|X_{e}-X_{s}\right|}{X_{e}}$

em que, $E_{r}$ - erro relativo; $X_{e}$ - valor obtido experimentalmente; $\mathrm{X}_{\mathrm{s}}$ - valor simulado.

\section{Procedimentos experimentais}

Processaram-se sementes de milho híbrido nas espigas, da variedade AG 3010, colhidas e despalhadas manualmente. O produto, transportado em caminhões do campo à unidade de beneficiamento, foi processado no máximo com 12 horas após a colheita. As espigas sadias foram transferidas para duas câmaras. As sementes, nas espigas, foram submetidas ao processo de secagem, com ar a $40^{\circ} \mathrm{C}\left( \pm 5^{\circ} \mathrm{C}\right)$, até atingir o teor de água igual a $16 \%$ b.u. e, em seguida foram deixadas em repouso durante 12 horas e então debulhadas. A complementação da secagem, feita a granel, em três silos com sistema de distribuição radial de ar, à temperatura de $42^{\circ} \mathrm{C}\left( \pm 5^{\circ} \mathrm{C}\right)$, foi encerrada quando o teor de água médio das sementes atingiu valores inferiores a $13 \%$ b.u. A vazão específica de ar no secador de espigas foi de $44,8 \mathrm{~m}^{3} \mathrm{~min}^{-1} \mathrm{~m}^{-2} \mathrm{e}$, nos silos secadores de $5,9 \mathrm{~m}^{3} \mathrm{~min}^{-1} \mathrm{~m}^{-2}$. A secagem em cada silo foi considerada como um teste e não como repetição.

Nas avaliações foram considerados três procedimentos operacionais distintos para a secagem das sementes, denominados tratamentos. Cada um foi concluído depois da execução de três testes consecutivos:

Tratamento 1 - consistiu na secagem das espigas despalhadas, com exposição total ao ar aquecido, até atingir teor de água em torno de 13,0\%.

Tratamento 2 - inicialmente, as espigas foram submetidas ao pré-aquecimento, pelo aproveitamento do ar de exaustão proveniente da secagem em outras câmaras e, posteriormente, o fluxo foi invertido, insuflando-Ihes 0 ar aquecido diretamente na fornalha.

Tratamento 3 - as espigas foram secadas até atingir teor de água médio de $16 \%$, ficando em repouso por 12 horas e então debulhadas, sendo a complementação da secagem feita em silos secadores.

O teor médio de água foi obtido a partir do valor médio das amostras coletadas nas posições superior, mediana e inferior da massa de espigas. Foram utilizados, para a sua determinação, o método padrão em estufa a $105^{\circ} \mathrm{C}$, durante 24 horas (Brasil, 1992). As temperaturas do ar de secagem, de exaustão e da massa de sementes foram medidas utilizando-se um termômetro digital com precisão de $1^{\circ} \mathrm{C}$, e de sensores de cobreconstatan, de bitola 22 AWG. A temperatura e umidade relativa ambiente foram monitoradas por meio de termohigrógrafo equipado com sensor eletrônico, com precisão de $1^{\circ} \mathrm{C}$ e $1 \%$, respectivamente.
As câmaras destinadas à pré-secagem das espigas, construídas em alvenaria, mediam $6,0 \mathrm{~m}$ de comprimento, $3,8 \mathrm{~m}$ de largura e $5,0 \mathrm{~m}$ de altura. Possuíam fundo de tela metálica, instalada com inclinação de $15^{\circ}$. A parte superior era construída de laje pré-moldada e possuía duas aberturas sendo uma para carga e outra para exaustão de ar. Nas laterais, tangentes às câmaras, dois dutos sobrepostos conduziam o ar do sistema de aquecimento até a massa de espigas. Na parede das câmaras, adjacentes aos dutos, existiam aberturas superiores e inferiores, providas de registros, que possibilitavam a passagem do ar através da massa de espigas, em sentido ascendente ou descendente, conforme o desenvolvimento da operação (Figura 2).

A amostragem de sementes nas câmaras foi realizada em intervalos de quatro horas. A amostra inicial foi obtida durante 0 carregamento. Durante a secagem, foram amostradas a porção superior, mediana e inferior da camada de espigas. As espigas foram coletadas aleatoriamente nessas posições.

No secador de sementes de milho a granel, ar foi distribuído através de um duto vertical perfurado, com diâmetro de $1,0 \mathrm{~m}$, instalado no centro geométrico do silo, onde $o$ ar era forçado a passar radialmente pela massa de sementes sob a ação de um obstruidor de fluxo. Um sistema de alavanca e roldanas permitia que o obstruidor fosse movimentado ou fixado na posição desejada, em qualquer altura da coluna de sementes, cuja espessura era $0,6 \mathrm{~m}$. Os silos secadores, adquiridos no mercado, foram construído em madeira e metal. Possuíam diâmetro externo de 2,2 $\mathrm{m}$ e altura de 6,0 m, (Figura 3).

As amostras, no sistema de secagem em silos, foram coletadas em intervalos de quatro horas e, a inicial, durante o carregamento. Durante a secagem, as amostra foram coletadas a 1 e $3 \mathrm{~m}$ em relação à altura da coluna de sementes, e a $1 \mathrm{~m}$ do topo. Um amostrador foi colocado estrategicamente nas paredes dos silos para esse fim.

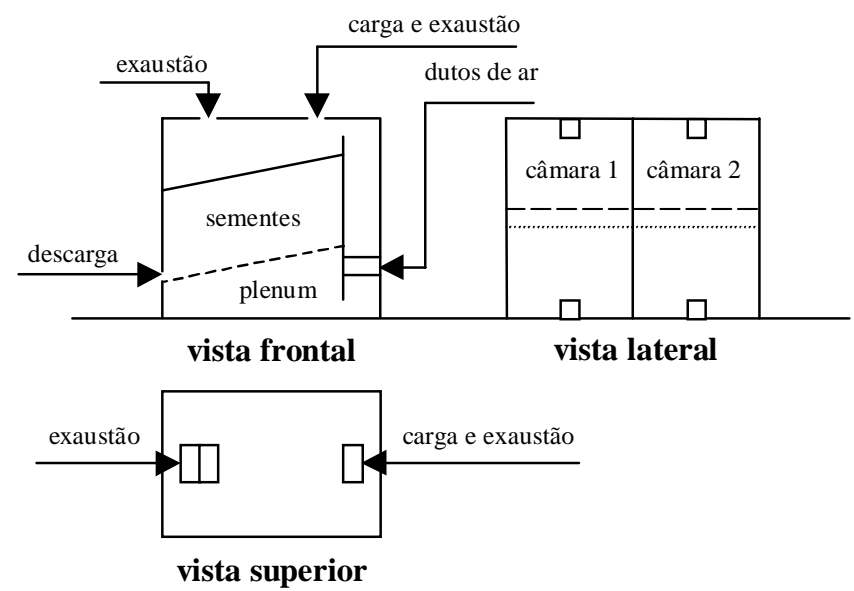

Figura 2 - Esquema do sistema de secagem das sementes, nas espigas, mostrando duas câmaras. 


\section{RESULTADOS E DISCUSSÃO}

A Figura 4 apresenta os resultados observados e simulados dos teores médios de água das sementes durante a secagem, no primeiro teste no tratamento 1. As configurações das curvas obtidas com os resultados observados e simulados apresentam-se semelhantes, no primeiro teste do tratamento 1 , com erro relativo médio de $11,56 \%$. A curva experimental mostra um período de secagem com taxa decrescente, com algumas oscilações decorrentes do sistema de controle operacional. A curva representando os resultados simulados superestimou a taxa de secagem no período entre 0 e 50 horas, e subestimou a partir desse período.

No pré-aquecimento, os resultados simulados e observados foram próximos, apresentando erro relativo médio de 3,62\% (Figura 5). Os resultados simulados tenderam a valores médios de teores de água inferiores àqueles observados experimentalmente (Figura 5A).

No estádio de secagem, ambas as curvas apresentaram configurações semelhantes, representando um erro relativo médio de $15,67 \%$. Os resultados simulados apresentaram-se superiores aos obtidos experimentalmente. Isso demostra que o modelo de simulação desenvolvido é consistente (Figura 5B). Observando os dados médios de teores de umidade no pré-aquecimento e secagem, verificou-se erro relativo médio de $9,64 \%$ (Figura 5 ).

$\mathrm{Na}$ fase de pré-secagem das sementes nas espigas (Figura 6A), para as condições de teste, 0 modelo apresentou uma resposta satisfatória em relação aos resultados observados, apresentando erro relativo médio de $3,27 \%$. Após 28 horas de présecagem, os teores de umidade das sementes observados e simulados aproximaram-se de $16,1 \%$. No sistema de secagem a granel (Figura 6B), com distribuição radial de ar, o modelo respondeu satisfatoriamente, apresentado erro relativo médio de $7,98 \%$.

A diferença entre os resultados simulados e experimentais de secagem das sementes a granel (Figura 6B), pode estar associada à uniformidade de distribuição do ar ao longo do duto central do secador. No modelo implementado assumiu-se que o ar era distribuído uniformemente ao longo do duto. Entretanto, experimentalmente verificou-se que principalmente no terço superior do silo as sementes atingiram menores valores de teor de água no final da secagem.

Ocorreu aumento na temperatura das sementes e pelos resultados simulados, houve tendência ao equilíbrio, para as mesmas condições (Figura 7). No início da secagem, as sementes com teor de água elevado, os valores simulados de temperatura foram superiores aos experimentais. Esta condição inverte-se, no final do processo, quando o teor de água é reduzido. Sob ponto de vista físico, este é o comportamento

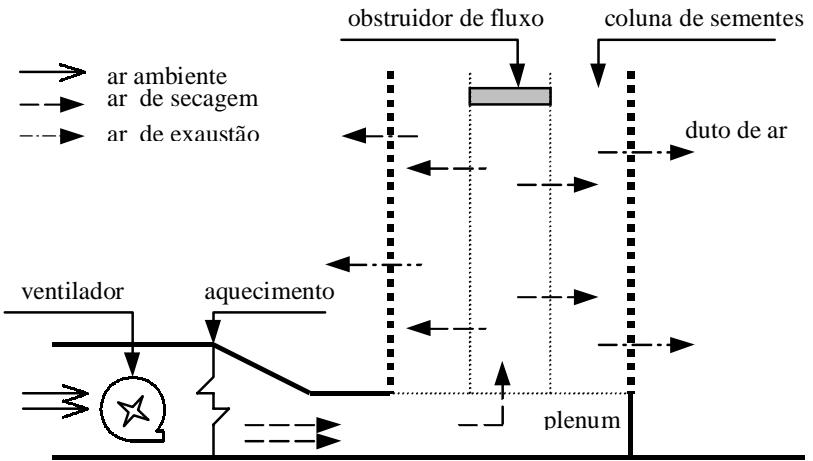

Figura 3 - Sistema de secagem em silos secadores, com distribuição radial de ar.

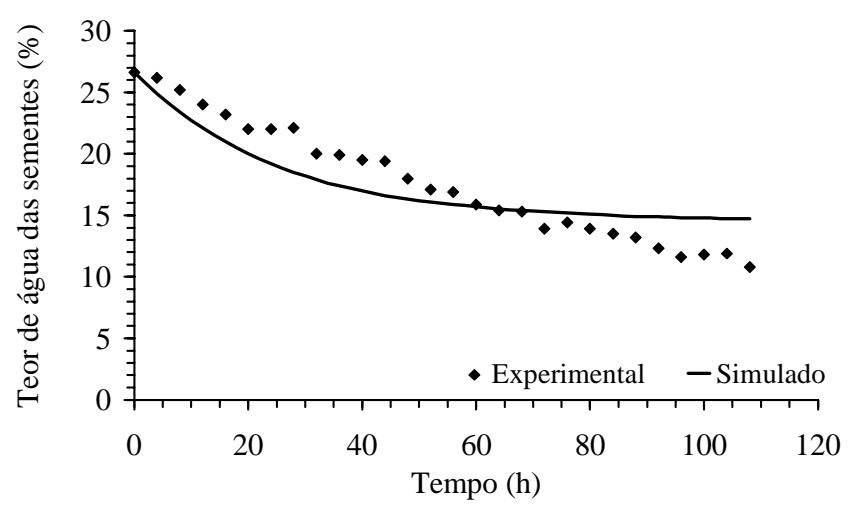

Figura 4 - Resultados observados e simulados dos teores médios de água durante a secagem, no primeiro teste no tratamento 1 .
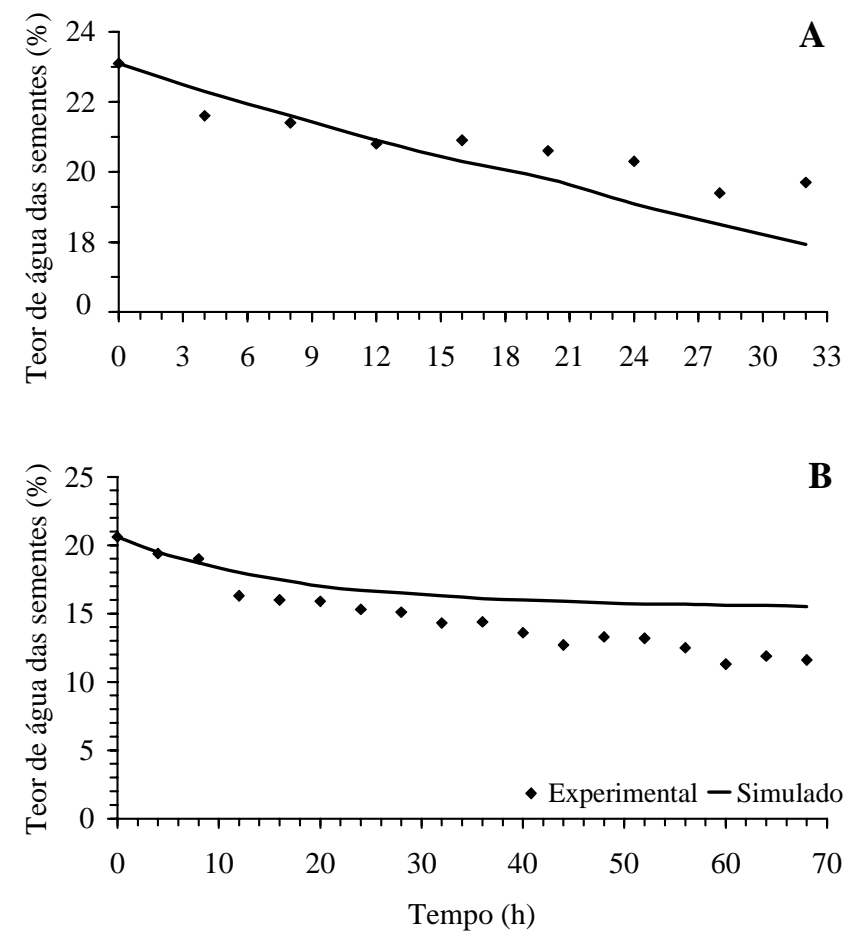

Figura 5 - Resultados observados e simulados dos teores médios de água nas fases de pré-aquecimento $(A)$ e secagem (B), no primeiro teste do tratamento 2 . 
esperado, embora a sensibilidade do modelo não fosse suficiente para retratá-lo. O erro relativo médio observado nesse tratamento foi de $12,06 \%$. No início, o maior teor de água das sementes permitiu maior incremento na razão de mistura do ar e, em conseqüência, redução na temperatura. No final do processo, com redução na taxa de secagem e o conseqüente declínio no incremento da razão de mistura, a temperatura entre 0 ar e as sementes tendeu ao equilíbrio.

$\mathrm{Na}$ fase de pré-aquecimento, a massa de espigas recebeu ar de exaustão, em fluxo ascendente, enquanto, na fase de secagem, recebeu o ar da fornalha, em fluxo descendente (Figura 8). Este comportamento parece ter contribuído para respostas mais consistentes do modelo, que apresentou erro relativo médio de $3,16 \%$.

A redução gradativa do teor de água não proporcionou os mesmos incrementos na temperatura da massa de sementes, conforme observado no tratamento 1. Este comportamento pode sugerir que 0 pré-aquecimento, associado à reversão no fluxo de ar, possa reduzir o estresse térmico das sementes durante a secagem.

Os resultados simulados e observados de temperatura das sementes obtidos no tratamento 3 são apresentados na Figura 9. Em comparação com os resultados observados, o modelo superestimou os valores de temperatura, para as duas fases. Os baixos valores de temperatura das sementes, verificada na fase de secagem a granel, ocorreu devido a erros experimentais. A inclinação da curva de temperatura simulada, na fase de secagem a granel, aumenta e depois permanece praticamente constante, visto que no modelo considerou-se que as sementes aumentariam de temperatura até atingirem o equilíbrio com o ar de secagem. Na fase de présecagem o modelo apresentou erro relativo médio na determinação da temperatura das sementes de 16,98\% e na fase de secagem de $28,38 \%$, com média de $22,68 \%$.

O modelo de simulação desenvolvido apresentou erro relativo médio de $10,88 \%$, inferior àquele considerado satisfatório por Mata \& Dantas (1998), que é de no máximo $20 \%$.

As variedades e condições experimentais podem ter contribuído para que os resultados simulados diferissem dos experimentais, pois como o trabalho foi conduzido em escala comercial não foi possível atender à padronização adotada por Sharaf-Eldeen et al. (1980), na determinação da equação de teor de água de equilíbrio para as sementes de milho nas espiga. Assim, equações de teor de água de equilíbrio obtidas sem critério de seleção de espigas, como o número determinado de espigas com o mesmo comprimento e volume, possivelmente levariam a resultados simulados mais satisfatórios.
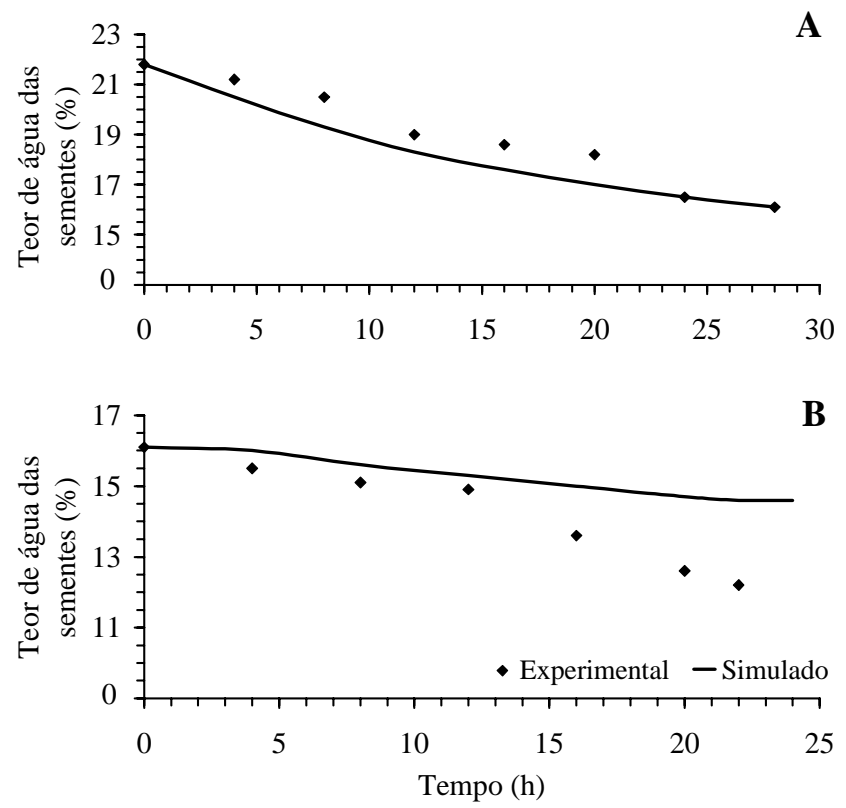

Figura 6 - Resultados observados e simulados dos teores médios de água nas fases de pré-secagem nas espigas (A) e secagem a granel $(B)$, no primeiro teste do tratamento 3.

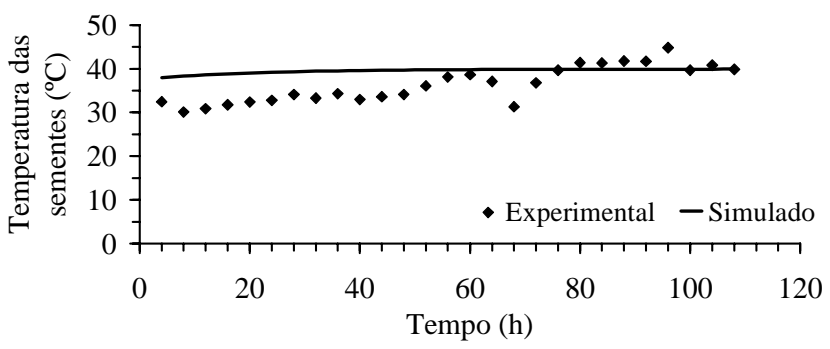

Figura 7 - Variação média entre a temperatura simulada e observada das sementes durante a secagem, no primeiro teste do tratamento 1 .
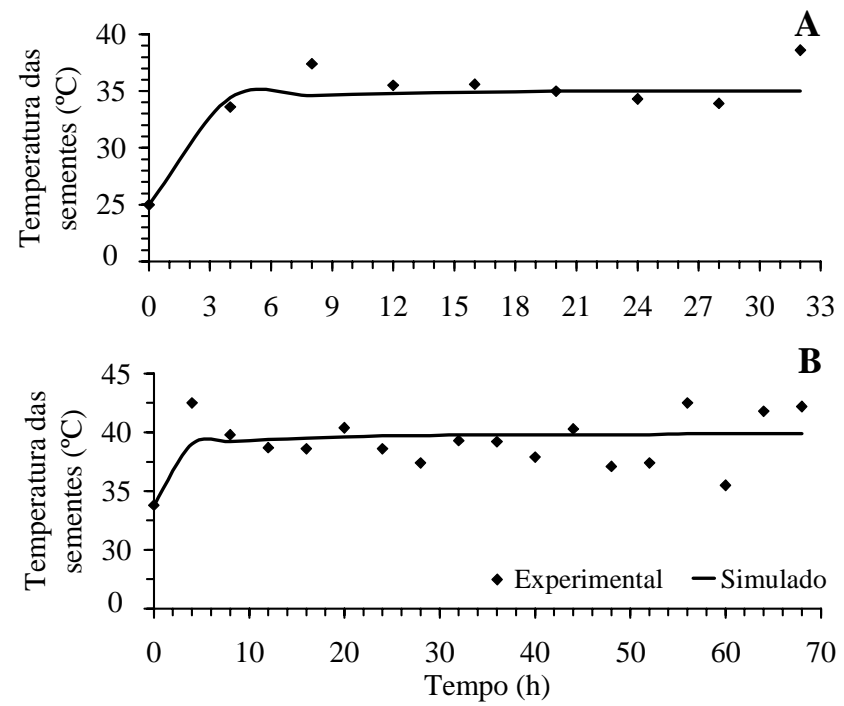

Figura 8 - Variação entre a temperatura simulada e observada das sementes, com o tempo, no pré-aquecimento $(A)$ e secagem (B), durante a realização do primeiro teste do tratamento 2 . 


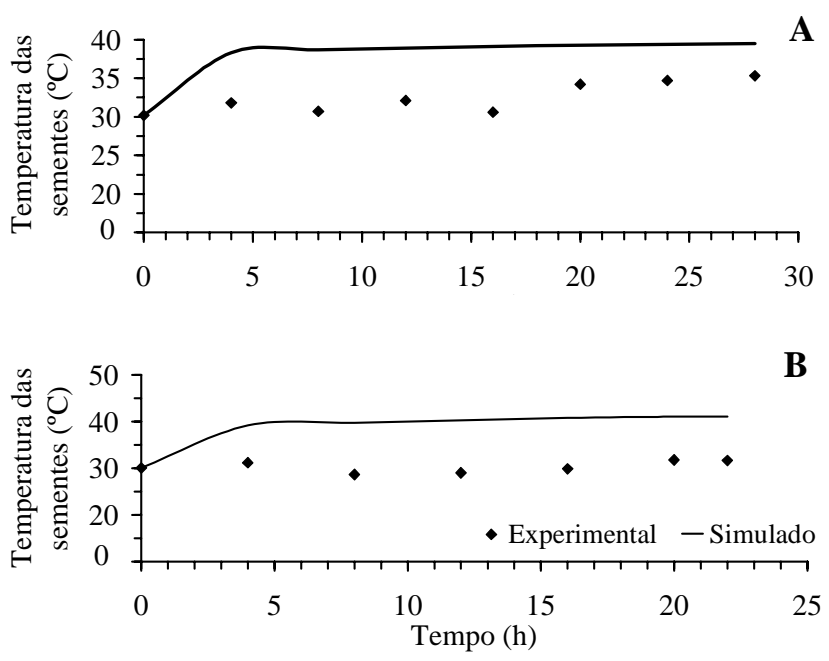

Figura 9 - Variação com o tempo, entre a temperatura simulada e observada das sementes, na pré-secagem (A) e secagem a granel $(B)$, durante a realização no primeiro teste do tratamento 3 .

\section{CONCLUSÕES}

O emprego de técnicas matemáticas e computacionais mostrou-se viável para simular a secagem de sementes de milho, apresentando precisão e exatidão satisfatória, sendo o modelo de simulação desenvolvido e validado, pois apresentou erro relativo médio igual a $10,88 \%$. Os modelos de Thompson e de Sharaf-Eldeen são válidos para simular a secagem de sementes de milho nas espigas, em secadores de leito fixo. Entretanto, há necessidade de obtenção de novas constantes para a equação de teor de água de equilíbrio para sementes de milho nas espigas, sem critério de seleção. O uso da técnica de simulação matemática apresenta-se como ferramenta disponível e viável para o dimensionamento de sistemas de secagem de sementes de milho nas espigas, considerando-se as características observadas para os sistemas utilizados experimentalmente.

\section{REFERÊNCIAS BIBLIOGRÁFICAS}

AMERICAN SOCIETY OF AGRICULTURAL ENGINEERS. ASAE Standards D271.2. St. Joseph: ASAE, 1998. p.24-31.

BRASIL. Ministério da Agricultura e Reforma Agrária. Regras para análise de sementes. Brasília, DF, 1992. 365p.

BROOKER, D.B.; BAKKER-ARKEMA, F.W.; HALL, C.M. Drying and storage of grains and oilseeds. New York: Van Nostrand Reinhold. 1992. 450p.

DAMACENO, G.S.; MOREIRA, S.M.C.; FORTES, M. Método simples para avaliação de equações de isotermas e entalpia de sorção e vaporização de água em materiais biológicos. In: ENCONTRO NACIONAL DE SECAGEM, 6., Viçosa, 1981. Anais. Viçosa: Centro Nacional de Treinamento em Armazenagem.1981. p.70-86.

MATA, M.E.R.M.C.; DANTAS, L.A. Modelo de simulação de secagem de cacau (Theobroma cacao L.) em camada fixa. Revista Brasileira de Armazenamento, v.23, p.52-60, 1998.

MICROSOFT VISUAL BASIC. Programming System for Windows, version 6. Redmond: Microsodft Corporation, 1998. 1 CDRom.

MONTROSS, M.D.; MONTROSS, J.E.; BAKKER-ARKEMA, F.W.; HINES, R.E. Dryer performance enhancement through grain preheating. Transactions of the ASAE, v.40, p.1391-1394, 1997.

QUEIROZ, D.M. Simulação de secagem de milho (Zea mays $\mathrm{L}$.) em secadores de fluxos concorrentes. Viçosa, 1984. 84p. Dissertação (M.S.) Universidade Federal Viçosa.

QUEIROZ, D.M.; CORRÊA, P.C.; SOUZA, C.M.A. SIMSEC - Um programa para simulação de secagem. In: CONFERÊNCIA BRASILEIRA DE PÓSCOLHEITA, 1., Porto Alegre, 1999. Anais. Passo Fundo: Abrapós; Cesa; Embrapa Trigo, 1999. p.248.

ROSSI, S.J.; ROA, G. Secagem e armazenagem de produtos agropecuários com uso de energia solar e ar natural. São Paulo: ACIESP, 1980. 295p.

SHARAF-ELDEEN, Y.I.; BLAISDEL, J.L.; HANDY, M.Y. A model for ear corn drying. Transactions of the ASAE, v.23, p.1261-1265, 1980.

THOMPSON, T.L.; PEART, R.M., FOSTER, G.H. Mathematical simulation of corn drying. A new model. Transaction of the ASAE, v.11, p.582-586, 1968.

TOLEDO, F.F.; MARCOS FILHO, J. Manual de sementes: tecnologia de produção. São Paulo: Editora Agronômica Ceres, 1977. 224p.

$\overline{\text { Recebido em 07.12.01 }}$ 